\title{
Cancer of the ampulla of Vater: chromosome 17p allelic loss is associated with poor prognosis
}

\author{
A Scarpa, C Di Pace, G Talamini, M Falconi, N R Lemoine, C Iacono, A Achille, \\ A Baron, G Zamboni
}

\begin{abstract}
Background-Cancer of the ampulla of Vater kills $60 \%$ of affected patients. Local spread of the tumour ( $T$ stage) is the only reliable prognostic factor. Nevertheless, any cancer stage includes long term survivors and patients dying from the disease. The molecular anomalies involved in this process have the potential to serve as additional prognostic markers.

$\mathrm{Aim}$ - To evaluate if allelic losses (LOH) of chromosomes $17 p$ and $18 q$ may be of prognostic value in multivariate survival
\end{abstract} analysis.

Methods-We examined 53 ampullary cancers for chromosome $17 p$ and $18 q$ LOH using microsatellite markers and DNA from paraffin embedded tumours. All patients were treated by surgery alone (pancreaticoduodenectomy). Multivariate survival analysis included age, sex, tumour size, macroscopic appearance, grade of differentiation, $T$ stage, lymph node metastasis, and chromosome $17 p$ and $18 q$ status.

Results-Chromosome 17p and 18q LOH were detected in 28 (53\%) and 18 (34\%) cancers, respectively. Multivariate survival analysis indicated chromosome $17 p$ status as an independent prognostic factor together with $T$ stage. The five year survival for chromosome $17 p$ retention and $17 \mathrm{p}$ loss was $80 \%$ and $7 \%$, respectively. The risk of death from cancer within the five year follow up period for patients with cancers harbouring chromosome $17 \mathrm{p}$ LOH was 11 times higher than that of patients with cancers retaining chromosome $17 p(p<0.0001)$, regardless of the tumour stage at diagnosis.

Conclusions-Chromosome 17p status is an independent prognostic factor among ampullary cancers at the same stage. The combined use of $T$ stage and chromosome $17 p$ status may help in deciding whether ampullary cancer patients require additional therapy other than surgery alone. (Gut 2000;46:842-848)

Keywords: ampulla of Vater; cancer; loss of heterozygosity; microsatellites; allelotyping; microsatellite instability Professor A Scarpa, Dipartimento di Patologia, Sezione Anatomia Patologica, Università di Verona, Strada Le Grazie, 8, I-37134 Verona, Italy. Email: scarpa@anpat.univr.it

Accepted for publication 21 December 1999

Patients with cancer of the ampulla of Vater account for up to $36 \%$ of those undergoing surgery for pancreaticoduodenal malignancies and are the only patients among those affected by cancers of biliopancreatic origin who have up to a $50 \%$ chance of being cured by surgery alone. ${ }^{1-8}$ There is general agreement that local spread of the tumour ( $\mathrm{T}$ stage) is the only significant and independent prognostic factor for this cancer whereas the predictive value of tumour grade and lymph node metastases is controversial. $^{1-8}$ Nevertheless, as any cancer stage includes both long term survivors and patients dying from the disease, the decision of whether therapy for ampullary cancer patients should be limited to surgery or include adjuvant therapies is subjective. There is undoubtedly a need for additional prognostic markers, and the molecular anomalies involved in this process ${ }^{6-12}$ have the potential to serve such a purpose.

As part of our continuing efforts designed to clarify the molecular pathogenesis of cancers of the ampulla of Vater, we have performed a genome wide survey of allelic losses $(\mathrm{LOH})$ on a limited number of cases for which DNA extracted from frozen tissues was available using site specific microsatellite markers on each chromosome. ${ }^{13}{ }^{14}$ Microsatellites are short repeat DNA sequences located throughout the genome $^{15}$ which may be readily assayed by polymerase chain reaction (PCR) amplification and gel electrophoresis. ${ }^{13}$ The two allelic forms of the microsatellites in normal cells, one inherited from each parent, migrate on gel electrophoresis as two bands of nearly equal intensity but different sizes. Loss of a chromosome in tumour tissue causes loss of one of the two PCR products (see fig 1). During these studies we noticed that allelic losses of the short arm (p) of chromosome 17 and of the long arm (q) of chromosome 18, at sites including or closely linked to $p 53$ and DCC/DPC4 (deleted in colon cancer/deleted in pancreatic cancer) genes, respectively, seemed to be associated with advanced stage cancers and poor outcome. This observation prompted us to evaluate if these chromosomal anomalies might be of prognostic value in a larger series of patients for which only archival formalin fixed, paraffin embedded samples were available.

\section{Materials and methods}

SELECTION OF CASES

Fifty three cancers of the ampulla of Vater, observed at the Verona University Hospital (Italy) between 1986-1994, were selected by applying the following criteria: (a) unequivocal establishment of their origin from the anatomical structures forming the ampulla of Vater ${ }^{6-11}$;
Abbreviations used in this paper: $\mathrm{LOH}$, loss of heterozygosity; PCR, polymerase chain reaction; RER, replication error. 
(b) treatment of patients with curative intent by surgery alone, consisting of pancreaticoduodenectomy; (c) availability of follow up through direct contact at least once a year with the patient or his/her physician.

PATIENTS AND TUMOURS

The clinicopathological characteristics of the 53 cases are reported in table 1 . The patients comprised 37 males (70\%) and 16 females $(30 \%)$, with a mean age of 57 years (range 33-73). The tumour stage was based on pathological and clinical evaluation, which included preoperative radiography, computed tomography, and abdominal exploration at laparotomy. The staging system used was that of Yamaguchi and Enjoji ${ }^{16}: \mathrm{T}$ stage I, tumour restricted to within the muscle of Oddi; $T$ stage II, infiltration of duodenal submucosa; $\mathrm{T}$ stage III, involvement of duodenal muscularis propria; $T$ stage IV, infiltration of periduodenal fat and pancreas; $\mathrm{N}$, nodal metastases; and $\mathrm{M}$, blood borne metastases. All but three cancers (two colloid and one small cell carcinoma) were graded according to Achille and colleagues. ${ }^{6}$ Three cancers were well $(6 \%), 21$ moderately (42\%), and 26 poorly (52\%) differentiated. The average number of lymph nodes isolated from the surgical specimens was 11 (range 5-32) and nodal metastases were present in $23(43 \%)$ cancers.

Table 1 Clinicopathological data and results of genotypic studies according to disease stage and outcome at follow up

\begin{tabular}{|c|c|c|c|c|c|c|c|c|c|c|c|c|}
\hline \multirow[b]{2}{*}{ Case $^{a}$} & \multirow[b]{2}{*}{ Sex } & \multirow[b]{2}{*}{ Age } & \multirow[b]{2}{*}{ Macroscopy $y^{b}$} & \multirow[b]{2}{*}{ Size $(\mathrm{cm})$} & \multirow[b]{2}{*}{ Grade $^{c}$} & \multirow[b]{2}{*}{ Stage $e^{d}$} & \multirow[b]{2}{*}{ p53 IHC } & \multicolumn{2}{|c|}{ Allelic losses } & \multirow[b]{2}{*}{ RER phenotype } & \multirow{2}{*}{$\begin{array}{l}\text { Follow up } \\
\text { (months) }\end{array}$} & \multirow[b]{2}{*}{ Outcome } \\
\hline & & & & & & & & $17 p$ & $18 q$ & & & \\
\hline $\operatorname{ATp} 43$ & M & 63 & NU & 2 & M & II & - & Yes & No & No & 26 & DOD \\
\hline ATp 53 & M & 62 & NU & 2 & $P$ & III N & - & No & No & No & 64 & Alive \\
\hline ATp 33 & $\mathrm{~F}$ & 61 & $\mathrm{U}$ & 1.5 & M & II & + & No & No & Yes & 126 & Alive \\
\hline ATp 45 & $\mathrm{~F}$ & 55 & NU & 2 & W & III & - & Yes & No & No & 203 & Alive \\
\hline AT 12 & M & 37 & $\mathrm{U}$ & 1.5 & $\mathrm{P}$ & IV N & $-^{\star}$ & Yes & Yes & No & 7 & DOD \\
\hline AT 22 & M & 53 & NU & 3 & M & III N & $-E$ & No & Yes & No & 62 & Alive \\
\hline ATp 31 & M & 50 & $\mathrm{U}$ & 3.5 & $\mathrm{P}$ & IV N & - & Yes & No & No & 12 & DOD \\
\hline ATp 48 & M & 49 & NU & 2 & W & IV & + & No & No & No & 158 & Alive \\
\hline AT 18 & M & 36 & NU & 1.5 & $\mathrm{P}$ & IV & $-E$ & No & No & No & 12 & DOD \\
\hline ATp 34 & $\mathrm{~F}$ & 63 & NU & 4 & M & III N & + & Yes & Yes & No & 51 & DOD \\
\hline AT 25 & $\mathrm{~F}$ & 44 & $\mathrm{U}$ & 0.6 & $\mathrm{P}$ & III N & $-\mathrm{E}$ & No & No & Yes & 55 & Alive \\
\hline ATp 37 & M & 46 & $\mathrm{U}$ & 7 & $\mathrm{P}$ & IV N & + & Yes & Yes & No & 26 & DOD \\
\hline ATp 51 & $\mathrm{~F}$ & 48 & NU & 2 & M & IV & - & No & No & No & 18 & DOD \\
\hline ATp 40 & M & 60 & $\mathrm{U}$ & 2.5 & M & II & + & No & No & No & 107 & Alive \\
\hline ATp 49 & M & 58 & $\mathrm{U}$ & 2 & $M$ & IV & + & Yes & No & No & 16 & DOD \\
\hline AT 8 & M & 62 & $\mathrm{U}$ & 2 & - & IV N & $-\star$ & Yes & Yes & No & 6 & DOD \\
\hline ATp 39 & M & 61 & $\mathrm{U}$ & 4 & M & IV N & - & Yes & Yes & No & 12 & DOD \\
\hline ATp 52 & M & 69 & $\mathrm{U}$ & 1 & $\mathrm{P}$ & III N & + & Yes & No & No & 29 & DOD \\
\hline AT 5 & M & 57 & $\mathrm{U}$ & 2.5 & $\mathrm{P}$ & IV N & $+\mathrm{E}$ & Yes & No & No & 4 & DOD \\
\hline ATp 54 & M & 47 & NU & 2.2 & $\mathrm{P}$ & III N & - & Yes & No & No & 22 & DOD \\
\hline AT 14 & M & 48 & $\mathrm{U}$ & 2 & M & III & $-\mathrm{E}$ & Yes & Yes & No & 22 & DOD \\
\hline ATp 44 & M & 33 & $\mathrm{U}$ & 2.5 & $\mathrm{P}$ & III & - & Yes & Yes & No & 24 & DOD \\
\hline AT 10 & M & 66 & $\mathrm{NU}$ & 2 & $M$ & II & $-\star$ & Yes & No & No & 85 & Alive \\
\hline ATp 57 & M & 69 & $\mathrm{U}$ & 2.5 & M & IV N & + & Yes & Yes & No & 19 & DOD \\
\hline AT 23 & $\mathrm{~F}$ & 68 & $\mathrm{U}$ & 3 & $\mathrm{P}$ & IV & $-\mathrm{E}$ & No & No & Yes & 55 & Alive \\
\hline ATp 38 & M & 64 & $\mathrm{U}$ & 4.5 & M & IV & + & No & No & No & 114 & Alive \\
\hline ATp 36 & M & 61 & NU & 2 & $\mathrm{P}$ & II & + & No & No & No & 184 & Alive \\
\hline AT 24 & M & 35 & $\mathrm{U}$ & 2 & $\mathrm{P}$ & II & $+\mathrm{E}$ & Yes & No & No & 31 & DOD \\
\hline AT 2 & M & 59 & $\mathrm{NU}$ & 1.5 & $\mathrm{P}$ & II & $-E$ & Yes & Yes & No & 20 & DOD \\
\hline AT 3 & M & 73 & $\mathrm{U}$ & 2 & M & III N & $+\mathrm{E}$ & Yes & Yes & No & 24 & DOD \\
\hline AT 4 & M & 66 & $\mathrm{U}$ & 1.5 & $\mathrm{P}$ & IV & $-E$ & No & No & No & 6 & DOD \\
\hline ATp 6 & M & 68 & $\mathrm{U}$ & 2.5 & M & IV & + & Yes & No & No & 16 & DOD \\
\hline ATp 59 & M & 47 & NU & 2 & $\mathrm{P}$ & IV N & + & Yes & No & No & 15 & DOD \\
\hline AT 16 & M & 49 & $\mathrm{U}$ & 1 & $\mathrm{P}$ & IV N & $-\mathrm{E}$ & No & No & No & 106 & Alive \\
\hline ATp 56 & M & 60 & NU & 1 & $\mathrm{P}$ & IV N & + & No & Yes & No & 21 & DOD \\
\hline ATp 50 & M & 72 & NU & 2 & - & IV & - & No & No & No & 116 & Alive \\
\hline ATp 29 & M & 59 & NU & 1.8 & $\mathrm{P}$ & IV N & + & Yes & Yes & No & 16 & DOD \\
\hline AT 15 & M & 44 & $\mathrm{U}$ & 1.8 & $\mathrm{P}$ & III N & $-E$ & Yes & No & No & 21 & DOD \\
\hline ATp 35 & $\mathrm{~F}$ & 65 & NU & 4 & - & IV & - & No & No & Yes & 130 & Alive \\
\hline ATp 13 & $\mathrm{~F}$ & 60 & $\mathrm{U}$ & 2 & $\mathrm{P}$ & IV N & + & Yes & Yes & No & 9 & DOD \\
\hline ATp 46 & M & 45 & NU & 2 & M & III & + & Yes & No & No & 23 & DOD \\
\hline ATp 58 & $\mathrm{~F}$ & 65 & $\mathrm{U}$ & 3.2 & $\mathrm{P}$ & IV N & - & No & No & No & 65 & Alive \\
\hline $\operatorname{AT} 7$ & $\mathrm{~F}$ & 46 & NU & 1 & $\mathrm{P}$ & II & $-\mathrm{E}$ & No & No & Yes & 119 & Alive \\
\hline ATp 42 & $\mathrm{~F}$ & 73 & NU & 1 & M & II & - & No & No & No & 48 & Alive \\
\hline AT 26 & $\mathrm{M}$ & 62 & NU & 1.5 & $M$ & III & $-E$ & No & No & Yes & 113 & Alive \\
\hline ATp 47 & $\mathrm{~F}$ & 61 & $\mathrm{U}$ & 2 & M & III & + & No & No & No & 74 & DOD \\
\hline AT 17 & $\mathrm{~F}$ & 57 & $\mathrm{NU}$ & 5 & W & II & $+\mathrm{E}$ & No & No & No & 78 & Alive \\
\hline ATp 55 & M & 63 & $\mathrm{U}$ & 2 & M & IV N & + & Yes & Yes & No & 25 & DOD \\
\hline ATp 30 & $\mathrm{~F}$ & 56 & NU & 1.5 & $\mathrm{P}$ & II & - & No & No & Yes & 63 & Alive \\
\hline $\operatorname{AT} 1$ & $\mathrm{~F}$ & 70 & $\mathrm{U}$ & 3.5 & $M$ & IV N & $+\mathrm{E}$ & Yes & Yes & No & 10 & DOD \\
\hline AT 27 & M & 69 & $\mathrm{U}$ & 3 & M & IV & $-E$ & No & Yes & No & 17 & DOD \\
\hline ATp 32 & M & 58 & $\mathrm{U}$ & 2.5 & $\mathrm{P}$ & IV & + & Yes & Yes & No & 7 & DOD \\
\hline AT 28 & $\mathrm{~F}$ & 50 & $\mathrm{U}$ & 4 & $\mathrm{P}$ & III & $+\mathrm{E}$ & No & No & Yes & 109 & Alive \\
\hline
\end{tabular}

${ }^{a} \mathrm{AT}$, ampullary tumour for which frozen tissue was available. ATp, cases with only paraffin embedded tissue.

${ }^{b} \mathrm{U}$, ulcerated; NU, non ulcerated.

'W, well differentiated; $M$, moderately differentiated; $P$, poorly differentiated.

${ }^{\mathrm{d}} \mathrm{I}$, intraductal; II, infiltration of duodenal submucosa; III, involvement of duodenal muscularis propria; IV, infiltration of periduodenal fat and pancreas; N, nodal metastases.

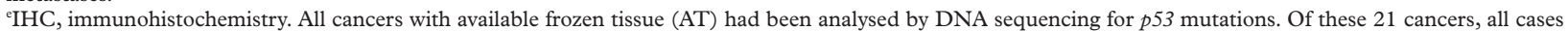
with p53 accumulation by IHC (+E) and three immunohistochemical negative cancers $(-\star)$ showed a p53 gene mutation, while no mutation was detected in the 12 remaining IHC negative cases $(-\mathrm{E})$ 
TISSUE AND DNA PREPARATION

Thick tissue sections $(6 \mu \mathrm{m})$ from formalin fixed, paraffin embedded surgical specimens were stained with haematoxylin and dried without a cover glass. They were soaked for five minutes in TE $(10 \mathrm{mM}$ Tris $\mathrm{HCl}, \mathrm{pH} 8.0,1$ mM EDTA) containing 1\% glycerol. Regions containing at least $70 \%$ cancer cells and matched normal mucosa were microdissected using a 27 gauge sterile needle and collected in $20 \mu \mathrm{l}$ of TE, $1 \%$ Tween 20 , and $200 \mu \mathrm{g} / \mathrm{ml}$ proteinase K. Samples were incubated overnight at $37^{\circ} \mathrm{C}$. After boiling for 10 minutes, $4 \mu \mathrm{l}$ aliquots were used for PCR amplification.

LOSS OF HETEROZYGOSITY AT 17p AND 18q CHROMOSOMAL ARMS

Twenty one previously reported cases, ${ }^{6}$ for which high quality DNA from frozen tissue was available, were analysed and compared with results obtained with the partially degraded DNA extracted from paraffin sections of the same cases. As the results correlated totally, we extended the study to the additional 32 cases for which only paraffin embedded tissue was available.

Allelic losses at chromosomes $17 \mathrm{p}$ and $18 \mathrm{q}$ were examined by PCR amplification of matched normal and cancer DNAs using four microsatellite markers for each chromosome: D17S513, D17S1176, D17S525, and D17S559 for chromosome 17p13, and microsatellites D18S61, D18S58, D18S64, and D18S69 for chromosome 18q21. All primers were from the MapPairs collection (Research Genetics, Huntsville, Alabama, USA). All cases were tested for D17S559, D17S1176, D18S69, and D18S64. Non-informative and negative scoring cases were subsequently tested for D17S513, D17S525, D18S61, and D18S58. The PCR reactions $(10 \mu \mathrm{l})$ were performed as previously described, ${ }^{11}{ }^{14}$ with modification for DNA from paraffin embedded tissues consisting of addition of five extra PCR cycles and an annealing temperature $5^{\circ} \mathrm{C}$ lower than that indicated by the primers' manufacturer. The radioactively labelled PCR products were analysed by polyacrylamide gel electrophoresis. ${ }^{14}$

Allelic losses were determined as previously detailed. ${ }^{14}$ Briefly, LOH was scored only when there was loss or diminished intensity of at least $60 \%$ of the bands representing one allele in the tumour sample with respect to the matched allele from normal tissue. Tumours yielding PCR products of abnormal sizes with four or more microsatellite markers were considered to belong to the replication error (RER) subclass. ${ }^{6}{ }^{17-20}$

\section{MUTATION OF THE p53 GENE}

The 21 cases for which DNA from frozen tissues was available had been previously characterised for $p 53$ mutations by PCR-single strand conformational polymorphism and direct DNA sequencing. ${ }^{611}$ However, these methods are difficult to apply to the partially degraded DNA from paraffin embedded tis-

A

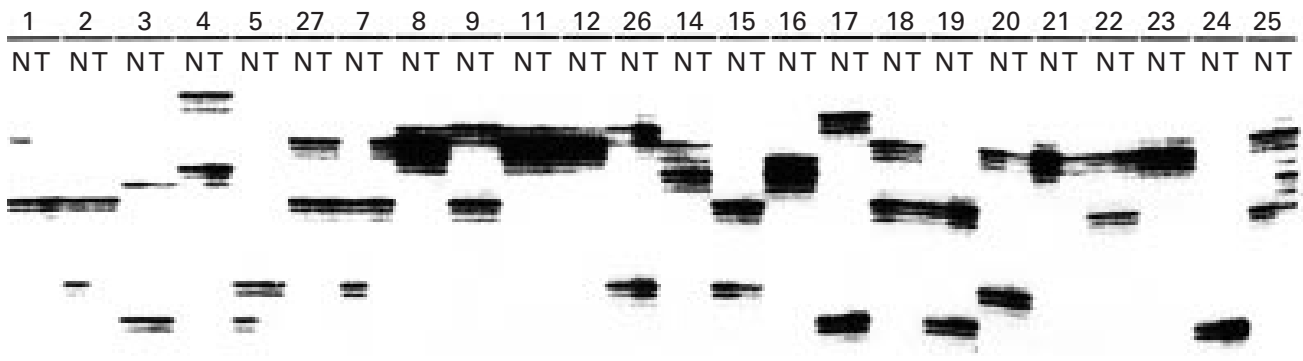

D17S559

B

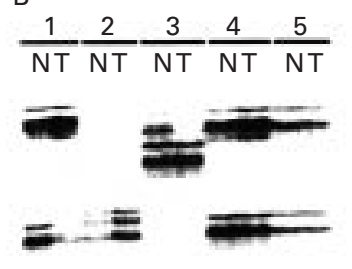

D18S64

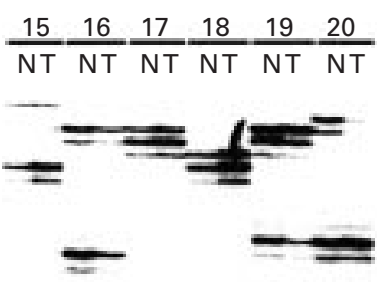

D18S61

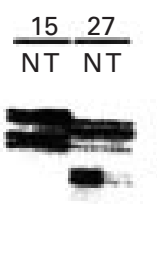

D18S58
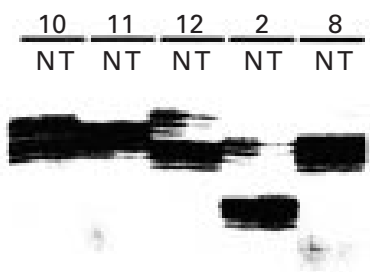

D18S69

Figure 1 (A) Analysis of polymerase chain reaction (PCR) amplified microsatellite locus D17S559, localised at chromosome $17 p 13$, using high molecular weight DNA from frozen tissues. Case numbers are indicated at the top of each lane and correspond to those of table 1. T, tumour; $N$, matched normal tissue DNA. The upper allele is lost in cancers 1,3 , 14 , and 20 whereas loss of the lower allele is evident in cancers 2, 5, and 15. Case Nos 4, 27, 9, 26, 17, 18, 19, and 22 show no losses. Case Nos 8,11,12, 16, 21, 23, and 24 were considered as non-informative. Cancers 7 and 25 are good examples of the possible findings in replication error (RER) positive neoplasms, showing the disappearance of one allele with the appearance of a new one, the presence of additional longer or shorter fragments, or a combination of these phenomena. Case Nos 9,11 , and 21 are three adenomas, two of which have been described previously. ${ }^{11}$ (B) Analysis of PCR amplified microsatellite loci of chromosome 18q, using DNA from formalin fixed, paraffin embedded tissues. Microsatellite loci are indicated at the bottom of each panel. Allelic losses occurred in cancers 1, 3, 19, 20, 27, 12, and 2. Case No 15 is an example of allelic imbalance due to the increased intensity of one allele in the absence of a decrease in intensity of the other. This case was considered as not having allelic loss as such a pattern may well be attributable to partial or total chromosomal gains (for example trisomies). Case No 11 is a previously described adenoma. ${ }^{9}$ 
sues. Therefore, we used immunocytochemistry with pAb1801 and DO7 anti-p53 monoclonal antibodies to assess the p53 mutational status in the 32 additional cases for which only paraffin embedded tissue was available. The rationale for this is that mutant proteins show a prolonged half life and it has been demonstrated that detection of $\mathrm{p} 53$ protein accumulation in cell nuclei serves as a surrogate for detection of $p 53$ gene mutations in gastrointestinal cancers. ${ }^{91}$ In particular, it recognises about $80 \%$ of $p 53$ gene mutated ampullary cancers. $^{6911}$ Specifically, when the threshold for positivity is set to staining over $30 \%$ of cancer cells, all cases showing immunohistochemical positivity had a mutation confirmed by direct sequencing. ${ }^{611}$ However, it should be recognised that false negative results occur in up to $20 \%$ of cases (see table 1, column p53 IHC).

FOLLOW UP AND STATISTICAL ANALYSIS

The primary statistical outcome in this study was overall survival measured from the date of surgery. Death from cancer was the end point. No case was lost at follow up, which was updated to May 1998. Overall survival distribution was calculated by the product-limit method and analysed using the Mantel-Cox test. ${ }^{22}$ Multivariate survival analysis was performed using the Cox's proportional-hazard model. ${ }^{23}$ To select the more stringent model, we used a backward elimination procedure, including all conventional factors (age, sex, macroscopic features, size, grade, stage, and nodal metastases), p53 mutation status, and chromosome $17 \mathrm{p}$ and $18 \mathrm{q} \mathrm{LOH}$ status. The final model included only the factors consistently retaining significant $\mathrm{p}(<0.05)$ values. BMDP (BMDP Inc., Los Angeles, California, USA) and SPSS (SPSS Inc., Chicago, Illinois, USA) statistical programs were used.

\section{Results}

At diagnosis, 35 (66\%) cancers had extraduodenal local invasion ( $\mathrm{T}$ stage IV) or nodal metastases, and 18 (34\%) were confined to the duodenal wall ( $\mathrm{T}$ stages II and III) (see table 1). Twenty one of the 53 patients $(40 \%)$ were alive and well after a period ranging from 48 to 203 months, including 11 whose cancer was confined to the duodenal wall and 10 with advanced stage disease. All of the remaining 32 patients, suffering from either low or advanced stage cancers, died after a median period of 20 months (mean 18 months; range 4-74) following surgery.

LOSS OF HETEROZYGOSITY ANALYSIS

The results of the molecular study are summarised in table 1 and a representative analysis is shown in fig 1 where examples of interpretation are also detailed.

Chromosome $17 \mathrm{p}$ and $18 \mathrm{q} \mathrm{LOH}$ were detected in $28(53 \%)$ and $18(34 \%)$ cancers, respectively. In 15 of these cases both allelic losses coexisted, and this association correlated with the cancer stage; it was found in $17 \%$ (3/18) low stage and in 34\% (12/35) advanced stage cancers. The majority of patients whose cancer harboured chromosome 17p LOH (11/ 13) or $18 \mathrm{q} \mathrm{LOH} \mathrm{(2/3)} \mathrm{alone} \mathrm{died} \mathrm{from} \mathrm{the} \mathrm{dis-}$ ease. All 15 patients whose cancer showed coexistent chromosome $17 \mathrm{p}$ and $18 \mathrm{q}$ allelic losses died.

Eight tumours showed microsatellite instability (fig 1) in 4-6 of the eight loci analysed and were classified as RER positive. ${ }^{6}$ The analysis of informative microsatellites not showing instability demonstrated that four of the eight RER positive ampullary tumours (AT7, AT23, AT26, ATp33) had retained both chromosome $17 \mathrm{p}$ alleles and four cases had retained both chromosome 18q copies (AT23, AT26, AT28, ATp35) (table 2). The five cases for which high molecular weight DNA was available were assessed for allelic losses at chromosome $17 \mathrm{p}$ by Southern blot analysis using the pYZ22 probe and MspI digestion. Only one case was informative (AT23) and the absence of $17 \mathrm{p}$ loss was confirmed in this case (data not shown). Finally, ATp35 showed no allelic loss by single strand conformation polymorphism analysis of the exon 6 polymorphic sequence of the $p 53$ gene (codon 213 , CGG, or CGA ${ }^{911}$ (data not shown). No additional case was informative for the two $p 53$ polymorphisms in intron 7 ( $\mathrm{C}$ to $\mathrm{T}$ and $\mathrm{T}$ to $\mathrm{G}$ at $71 \mathrm{bp}$ and $91 \mathrm{bp}$ downstream of exon 7 , respectively). In summary, we demonstrated that no chromosome $17 p$ and $18 q$ losses were found in five and four of the eight RER positive cases, respectively. Based on these results, and in accordance with Jen and colleagues, ${ }^{13}$ carcinomas of the RER type were included among the tumours with no loss of chromosomes $17 \mathrm{p}$ and $18 \mathrm{q}$ in the survival statistical analysis.

p53 IMMUNOHISTOCHEMISTRY

Abnormal accumulation of $\mathrm{p} 53$ protein was found in 25 cancers (47\%), all showing

Table 2 Detailed results of microsatellite markers analysis in the eight RER positive cancers

\begin{tabular}{|c|c|c|c|c|c|c|c|c|}
\hline \multirow[b]{2}{*}{ Case } & \multicolumn{4}{|l|}{ Chromosome $17 p$} & \multicolumn{4}{|l|}{ Chromosome $18 q$} \\
\hline & D17S559 & D17S1176 & D17S513 & D17S525 & D18S69 & D18S64 & D18S61 & D18S58 \\
\hline AT 7 & $\mathrm{MI}^{\mathrm{a}}$ & MI & Stable (no loss) & Not ampl. & MI & MI & Stable (ni) & MI \\
\hline AT 23 & MI & MI & Stable (no loss) & MI & Stable (ni) & Stable (no loss) & MI & MI \\
\hline AT 25 & MI & Stable (ni) & MI & MI & MI & MI & MI & Stable (ni) \\
\hline AT 26 & Stable (no loss) & MI & Not ampl. & Stable (no loss) & Not ampl. & MI & MI & Stable (no loss) \\
\hline AT 28 & Stable (ni) & MI & MI & MI & MI & Stable (ni) & Stable (no loss) & MI \\
\hline ATp 30 & MI & MI & MI & Stable (ni) & Stable (ni) & MI & MI & Not ampl. \\
\hline ATp 33 & MI & Stable (no loss) & MI & MI & MI & MI & Stable (ni) & MI \\
\hline ATp 35 & MI & MI & Stable (ni) & Not ampl. & Stable (no loss) & MI & MI & MI \\
\hline
\end{tabular}

${ }^{\mathrm{a}} \mathrm{MI}$, microsatellite instability. For the stable loci of chromosomes $17 \mathrm{p}$ and $18 \mathrm{q}$ their status is reported: ni, not informative; Not ampl, failure of PCR amplification of either normal or tumour DNA. 
Table 3 Multivariate statistical analysis (Cox's model)

\begin{tabular}{lllll}
\hline Variable & $\begin{array}{l}\text { No of } \\
\text { surviving } \\
\text { patients }\end{array}$ & $\begin{array}{l}\text { No of dead } \\
\text { patients }\end{array}$ & $\begin{array}{l}\text { Relative risk of death } \\
\text { from cancer* }(95 \% \text { CI) }\end{array}$ & p Value \\
\hline $\begin{array}{l}\text { Stage } \\
\text { II-III }\end{array}$ & 14 & 12 & 1 & - \\
IV & 7 & 20 & $4.78(2.20-10.38)$ & 0.0001 \\
$\begin{array}{l}\text { 17p } \\
\text { No loss }\end{array}$ & 19 & 6 & 1 & - \\
Loss & 2 & 26 & $11.30(4.24-30.11)$ & 0.0001 \\
\hline
\end{tabular}

${ }^{\star}$ Hazard ratio adjusted for age, sex, macroscopy, size, grade, stage, nodal metastases, p53 gene mutation, and chromosome18q LOH status.

Table 4 Multivariate statistical analysis (Cox's model) excluding eight RER positive patients (45 patients)

\begin{tabular}{lllll}
\hline Variable & $\begin{array}{l}\text { No of } \\
\text { surviving } \\
\text { patients }\end{array}$ & $\begin{array}{l}\text { No of dead } \\
\text { patients }\end{array}$ & $\begin{array}{l}\text { Relative risk of death } \\
\text { from cancer }\end{array}$ & p (95\% CI)
\end{tabular}

${ }^{\star}$ Hazard ratio adjusted for age, sex, macroscopy, size, grade, stage, nodal metastases, p53 gene mutation, and chromosome18q LOH status.

immunostaining in the majority of cancer cell nuclei and therefore suggestive of $p 53$ gene mutation (see materials and methods and table $1)$. There was no difference in the proportion of $p 53$ mutated cases between cancers confined to the duodenal wall $(8 / 18,44 \%$ of $\mathrm{T}$ stages II-III cases) and advanced stage diseases $(17 / 35,48 \%$ of $\mathrm{T}$ stage $\mathrm{IV}$ or $\mathrm{N}+$ cases) $(\mathrm{p}=0.17)$. Sixteen of the 25 cancers showing p53 mutations, as assessed by immunostaining, had complete loss of $\mathrm{p} 53$ function due to the concomitant loss of the normal p53 allele on chromosome $17 \mathrm{p}$. All of these 16 cancers caused the death of the patients, including two of 18 with early stage disease and 14 of 35 with advanced disease.

SURVIVAL ANALYSIS

The results of multivariate analysis are summarised in tables 3 and 4 and Kaplan-Meier sur-
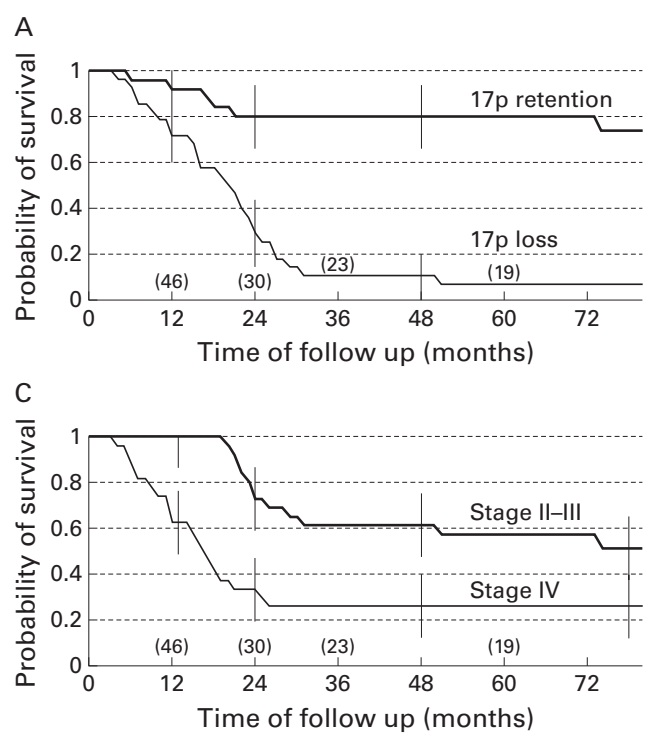

vival curves are shown in fig 2 . We first performed multivariate analysis using Cox's multiple regression model with inclusion of all conventional factors (age, sex, tumour size, macroscopic features, grade of differentiation, and lymph node metastasis), p53 mutation, and chromosome $17 \mathrm{p}$ and $18 \mathrm{q} \mathrm{LOH}$ status. In this analysis we included the RER positive cancers among those retaining both copies of chromosomes $17 \mathrm{p}$ and $18 \mathrm{q}$ (table 3 ). Only $\mathrm{T}$ stage and $17 \mathrm{p}$ status emerged as independent prognostic factors. The estimated risk of death from cancer within the five year follow up period for patients with extraduodenal local extension of disease ( $T$ stage IV) was 4.78 times higher than that of patients with their disease confined to the duodenal wall ( $\mathrm{T}$ stages II-III) (95\% CI $2.20-10.38 ; \mathrm{p}<0.0001)$. The relative risk of death for patients with cancers showing chromosome $17 \mathrm{p} \mathrm{LOH}$ was 11.3 times higher than that of patients with cancers retaining chromosome $17 \mathrm{p} \quad(95 \%$ CI $4.24-30.11$; $\mathrm{p}<0.0001)$. The median actuarial survival time was 16 months (95\% CI 13-19) for T stage IV and over 74 months for T stages II-III cases. The median actuarial survival time was 20 months (95\% CI 14-26) and 19 months (95\% CI 13-25) for cases with chromosome $17 \mathrm{p}$ and chromosome $18 \mathrm{q}$ allelic loss, respectively, whereas it was not measurable for cases retaining both copies of each of chromosome $17 \mathrm{p}$ or $18 \mathrm{q}$.

Both multivariate and univariate analysis showed no significant difference between survivors and non-survivors for age, sex, tumour size, macroscopic features, grade of differentiation, lymph node metastasis, or p53 gene mutations.

Exclusion of the eight RER positive cancers from the multivariate survival analysis did not alter the general results or the prognostic significance of chromosome 17p loss (table 4).

B

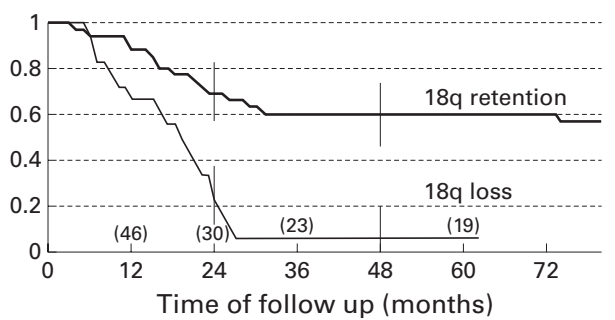

D

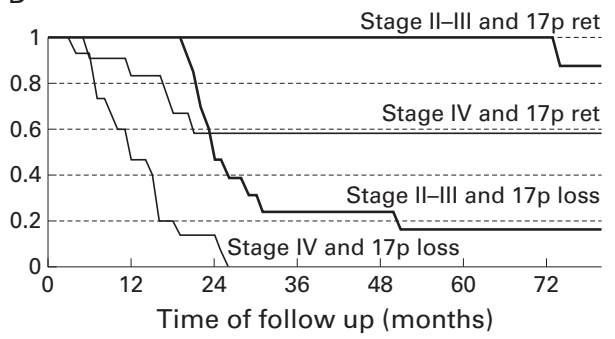

Figure 2 Survival curves obtained by the product-limit method. Better survival was associated with no loss of chromosome 17p $(p<0.0001)$ or $18 q(p<0.0001)(A, B)$ and T stages II-III compared with stage IV $(p<0.0001)(C)$. (D) Overall survival of patients according to both $T$ stage and chromosome $17 p$ status. Numbers in parentheses indicate the number of subjects at risk at different time intervals. Vertical lines indicate $95 \%$ confidence intervals. 


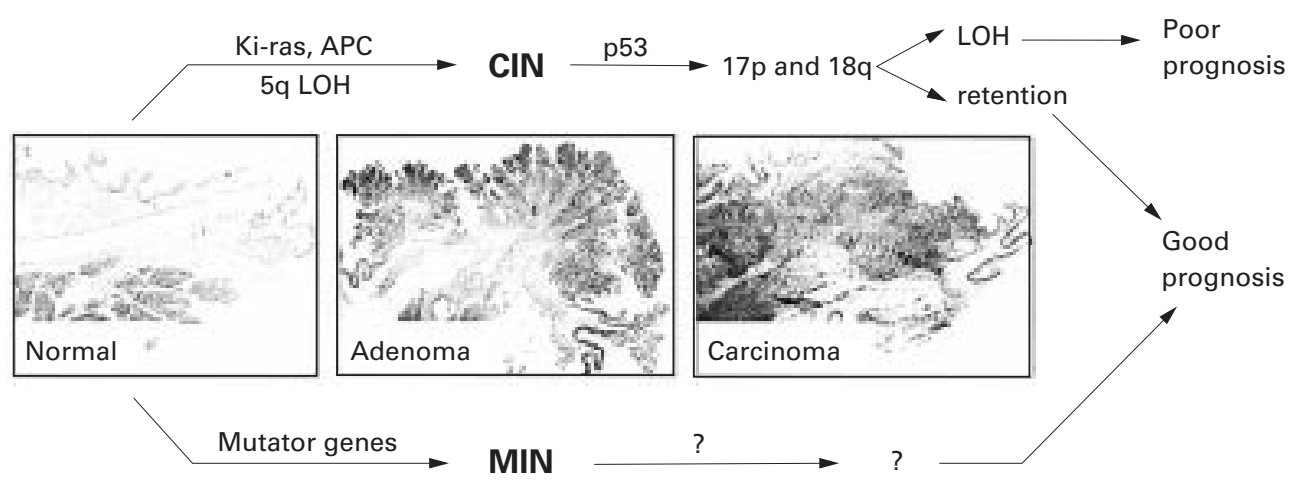

Figure 3 Molecular pathogenesis and prognosis of cancers of the ampulla of Vater. Ampulla of Vater cancers have similar molecular pathogenetic pathways as gastric and colorectal cancers. The majority of cases (85\%) show frequent chromosomal changes (CIN, chromosomal instability), while a subgroup (15\%) shows subtle widespread DNA alterations (MIN, microsatellite instability). In CIN type ampullary cancers, the early genetic events include mutation of the adenomatous polyposis coli (APC) and Ki-ras genes in $17 \%$ and $37 \%$ of cases, respectively, together with chromosome $5 q$ loss (50\%). ${ }^{9-12}$ Mutation of the p53 gene occurs in about 50\% of cases at the time of adenoma-carcinoma transition. ${ }^{6}{ }^{11}$ Allelic losses at chromosomes $17 p(51 \%)$ and $18 q(33 \%)$ are associated with progression of malignancy. MIN type ampullary cancers rarely show chromosomal losses. The two molecular pathways identify different prognostic categories. MIN ampullary cancers have a low aggressive potential, ${ }^{6}$ similar to that of CIN cancers, retaining both copies of chromosome $17 p$. Chromosome $17 \mathrm{p}$ loss is associated with a high risk of death from cancer within two years following surgery.

\section{Discussion}

Ampullary cancers are usually diagnosed when the tumour mass reaches about $2.5 \mathrm{~cm}$ in diameter. ${ }^{716}$ However, despite having a comparable tumour mass, they include neoplasms at different stages of evolution and with different levels of biological aggressiveness, which might be described by the associated genetic abnormalities. A schematic representation of the molecular pathogenesis of ampullary cancer is depicted in fig 3 which is based on the present data and on our previous published work with $\mathrm{Ki}$-ras, $p 53$, and adenomatous polyposis coli $(A P C)$ gene mutations, chromosome 5 allelic losses, and identification of a subset of ampullary cancers with widespread genomic alterations of the type seen in replication error phenotype (RER+) gastrointestinal cancers and good prognosis. ${ }^{6-12}$

Our study demonstrates that the allelic loss of chromosome $17 \mathrm{p}$ is an important prognostic marker in patients with cancer of the ampulla of Vater. The subgroup of patients whose tumour had retained both alleles of chromosome $17 \mathrm{p}$ ( $44 \%$ of patients) had a very good outcome (five year survival of $80 \%$ ) whereas survival in patients whose tumour had lost one allele of chromosome $17 \mathrm{p}$ was poor (five year survival of $7 \%$ ). The estimated risk of death from cancer within the five year follow up period for patients with cancers showing chromosome $17 \mathrm{p}$ loss was 11 times higher than that for patients with cancers retaining both alleles. Univariate statistics suggested that chromosome $18 \mathrm{q}$ status was also a prognostic indicator. However, multivariate survival analysis showed that its content of information was lower than that of chromosome $17 \mathrm{p}$ status.

Mutation of the $p 53$ gene, as assessed by immunohistochemical analysis, was not useful for determining prognosis in our series. Fourteen patients, who all died of disease, showed complete inactivation of p53 function by mutation of one allele and deletion of the chromosomal $17 \mathrm{p}$ locus containing the other. Inactivating mutation of one p53 allele is likely to occur at the time of the adenoma-carcinoma transition in ampullary cancers ${ }^{6}{ }^{9}$ whereas loss of the remaining normal $p 53$ allele on chromosome $17 \mathrm{p}$ is associated with advanced stage cancers. It is likely that the prognostic information of $17 \mathrm{p} \mathrm{LOH}$ resides in the identification of cancers with complete loss of p53 function - that is, of its gatekeeper function for cell proliferation. ${ }^{24}$

Our data suggest that chromosome $18 \mathrm{q}$ loss occurs at a later stage than chromosome $17 \mathrm{p}$ loss in ampullary cancers. This chromosomal loss is a frequent finding in duodenal, colorectal, and pancreatic cancer. ${ }^{13}{ }^{25-27}$ More than one candidate gene for this loss resides on 18q. DPC4 has been suggested as a main target in pancreatic cancer. ${ }^{27}{ }^{28}$ In colon cancer either $D C C, D P C 4$, and/or $M A D$ (mothers against decapentaplegic) related 2 gene have been suggested to be the targets of deletion (see Martinez-Lopez and colleagues ${ }^{26}$ ). There is no information as yet on the candidate gene on chromosome 18q in ampullary cancer.

In addition to the status of chromosome $17 \mathrm{p}$, only the $\mathrm{T}$ stage - that is, the local invasiveness of the tumour-had an independent prognostic value among the conventional factors considered here. The estimated risk of death from cancer within the five year follow up period for extraduodenal diseases (T stage IV) was almost five times higher than that for cancers confined to the duodenal wall ( $\mathrm{T}$ stages II-III). Our finding that local invasion describes the clinical aggressiveness of ampullary cancers better than any other conventional factor is in line with five other studies. ${ }^{1-4}{ }^{6}$ Previous studies suggesting a prognostic value for lymph node metastases used either univariate statistics alone or evaluated only the size and not the local aggressiveness of the tumour ( $\mathrm{T}$ stage). ${ }^{3729}$ The use of cancer grading as an additional prognostic factor has led to inconsistent results ${ }^{1-467}$ which may be attributed to both lack of clear cut criteria and the subjectivity involved in the definition of grading categories. 
The clinical importance of the assessment of both $\mathrm{T}$ stage and chromosome $17 \mathrm{p}$ status in cancers of the ampulla of Vater resides in the capacity of the latter to discriminate between patients with good and poor prognosis within the same stage. Patients with the disease confined to the duodenal wall ( $\mathrm{T}$ stages II-III) and retention of both chromosome $17 \mathrm{p}$ alleles had a much better outcome $(100 \%$ five year survival) than those with chromosome $17 \mathrm{p}$ allelic loss (18\% five year survival). Similarly, patients with extraduodenal cancers ( $\mathrm{T}$ stage IV) retaining chromosome $17 \mathrm{p}$ alleles had a five year survival of $60 \%$ whereas none of those with chromosome $17 \mathrm{p}$ allelic loss survived the second year following surgery.

Eight tumours in the present series were classified as RER positive as they showed widespread microsatellite instability and were associated with an excellent five year survival as those early stage cancers retaining chromosome $17 \mathrm{p}(100 \%)$. This finding confirms and extends our previous report on the good prognosis associated with RER positive tumours. ${ }^{6}$ It is difficult to assess the chromosomal losses in RER positive tumours. However, we demonstrated that both copies of chromosomes $17 \mathrm{p}$ and $18 \mathrm{q}$ were retained in five and four of the eight RER positive cases, respectively. Other studies have shown that gastrointestinal RER positive tumours, including gastric, duodenal, and colorectal cancers rarely have chromosomal losses..$^{1318} 19{ }^{25} \mathrm{It}$ is tempting to speculate that the better outcome in patients with RER positive tumours is a result of retention of both chromosome $17 \mathrm{p}$ and $18 \mathrm{q}$ alleles. At any rate, exclusion of these eight RER positive cancers from the univariate and multivariate analysis did not alter the results of survival analysis, including the prognostic significance of chromosome $17 \mathrm{p}$ loss.

In conclusion, allelic losses at chromosomes $17 p$ and $18 q$ are frequent alterations involved in ampullary cancers and are associated with shortened patient survival. Chromosome 17p status is useful in predicting prognosis among cancers at the same stage. The combined use of $\mathrm{T}$ stage and chromosome $17 \mathrm{p}$ status may be useful in deciding whether or not ampullary cancer patients may require therapy in addition to surgery.

This study was supported by grants from Associazione Italiana Ricerca sul Cancro (AIRC), Milan, Italy; Consorzio per gl Studi Universitari, Verona, Italy; Banca Popolare di Verona, taly; by a co-financed grant from Verona University and Ministero Università e Ricerca Scientifica e Tecnologica (MURST) Rome, Italy; and European Community grant Biomed-2 CE-Contract No BMH4-CT98-3805.

1 Neoptolemos JP, Talbot IC, Shaw DC, et al. Long-term survival after resection of ampullary carcinoma is associated independently with tumor grade and a new staging classification that assesses local invasiveness. Cancer $1988 ; 61: 1403-7$.
2 Klempnauer J, Ridder GJ, Pichlmayr R. Prognostic factors after resection of ampullary carcinoma: multivariate survival analysis in comparison with ductal
pancreatic head. Br $\mathcal{F}$ Surg 1995;82:1686-91.

3 Roder JD, Schneider PM, Stein HJ, et al. Number of lymph node metastases is significantly associated with survival in patients with radically resected carcinoma of the ampulla of Vater. Br F Surg 1995;82:1693-6.

4 Allema JH, Reinders ME, van Gulik TM, et al. Results of pancreaticoduodenectomy for ampullary carcinoma and analysis of prognostic factors for survival. Surgery 1995; 117:247-53.

5 Shirai Y, Tsukada K, Ohtani T, et al. Carcinoma of the ampulla of Vater: histopathologic analysis of tumor spread in Whipple pancreatoduodenectomy specimens. World 7 Surg 1995;19:102-6.

6 Achille A, Biasi MO, Zamboni G, et al. Cancers of the papilla of Vater: mutator phenotype is associated with good prognosis. Clin Cancer Res 1997;3:1841-7.

7 Talamini MA, Moesinger RC, Pitt HA, et al. Adenocarcinoma of the ampulla of Vater. A 28-year experience. Ann Surg 1997;225:590-9.

8 Dorandeu A, Raoul JL, Siriser F, et al. Carcinoma of the ampulla of Vater: prognostic factors after curative surgery: a series of 45 cases. Gut 1997;40:350-5.

9 Scarpa A, Capelli P, Zamboni G, et al. Neoplasia of the ampulla of Vater. Ki-ras and p53 mutations. Am $\mathcal{F}$ Pathol 1993;142:1163-72.

10 Scarpa A, Zamboni G, Achille A, et al. ras-family gene mutations in neoplasia of the ampulla of Vater. Int $\mathcal{F}$ Cancer 1994;59:39-42.

11 Achille A, Scupoli MT, Magalini AR, et al. APC gene mutations and allelic losses in sporadic ampullary tumours: evidence of genetic difference from tumours associated with familial adenomatous polyposis. Int 7 Cancer 1996;68:30512.

12 Achille A, Baron A, Zamboni G, et al. Chromosome 5 allelic losses are early events in tumours of the papilla of Vater and occur at sites similar to those of gastric cancer. $\mathrm{Br} \mathcal{F}$ Cancer 1998;78:1653-60.

13 Jen J, Kim H, Piantadosi S, et al. Allelic loss of chromosome $18 \mathrm{q}$ and prognosis in colorectal cancer. $N$ Engl $7 \mathrm{Med}$ 1994;331:213-21.

14 Achille A, Biasi MO, Zamboni G, et al. Chromosome 7q allelic losses in pancreatic carcinoma. Cancer Res 1996;56: 3808-13.

15 Beckman JS, Weber JL. Survey of human and rat microsatellites. Genomics 1992;12:627-31.

16 Yamaguchi K, Enjoji M. Carcinoma of the ampulla of Vater. A clinicopathologic study and pathologic staging of 109 cases of carcinoma and 5 cases of adenoma Cancer 1987;59:506-15.

17 Ionov Y, Peinado MA, Malkhosyan S, et al. Ubiquitous somatic mutations in simple repeated sequences reveal a somatic mutations in simple repeated sequences reveal a 363:558-61.

18 Aaltonen LA, Peltomaki P, Leach FS, et al. Clues to the pathogenesis of familial colorectal cancer. Science 1993; 260:812-16

19 Thibodeau SN, Bren G, Schaid D. Microsatellite instability in cancer of the proximal colon. Science 1993;260:816-19.

20 Peltomaki P, Lothe RA, Aaltonen LA, et al. Microsatellite instability is associated with tumors that characterize the hereditary non-polyposis colorectal carcinoma syndrome. Cancer Res 1993;53:5853-5.

$21 \mathrm{Kim} \mathrm{H}$, Jen J, Vogelstein B, et al. Clinical and pathological characteristics of sporadic colorectal carcinomas with DNA replication errors in microsatellite sequences. $A m \mathcal{F}$ Pathol 1994;145:148-56.

22 Armitage B, Berry G. Statistical methods in medical research. Oxford: Blackwell Scientific Publications, 1987:421-39.

23 Cox DR. Regression models and life-tables. $\mathcal{F} R$ Stat Soc [B] 1972;34:187-220.

24 Levine AJ. p53, the cellular gatekeeper for growth and division. Cell 1997;88:323-31.

25 Achille A, Baron A, Zamboni G, et al. Molecular pathogenesis of sporadic duodenal cancer. Br f Cancer 1998;77:7605.

26 Martinez-Lopez E, Abad A, Font A, et al. Allelic loss on chromosome $18 \mathrm{q}$ as a prognostic marker in stage II colorectal cancer. Gastroenterology 1998;114:1180-7.

27 Rozenblum E, Schutte M, Goggins M, et al. Tumorsuppressive pathways in pancreatic carcinoma. Cancer Res 1997;57:1731-4.

28 Hahn SA, Schutte M, Hoque AT, et al. DPC4, a candidate tumor suppressor gene at human chromosome 18q21.1. Science 1996;271:350-3.

29 Howe JR, Klimstra DS, Cordon-Cardo C, et al. K-ras mutation in adenomas and carcinomas of the ampulla of Vater. Clin Cancer Res 1997;3:129-33. 